\title{
SPL Blood Form Establishment Type Terminology
}

National Cancer Institute

\section{Source}

National Cancer Institute. SPL Blood Form Establishment Type Terminology. NCI

Thesaurus. Code C133242.

Terminology used to qualify the information pertaining to blood form establishments in the framework of the Structured Product Labeling documents. 